\title{
The Role and Importance of Marketing in South African Township SMMEs
}

\author{
Prof. M. C. Cant \\ Department of Marketing and Retail Management \\ University of South Africa, South Africa \\ Prof. J. A. Wiid \\ Department of Marketing and Retail Management \\ University of South Africa, South Africa
}

DOI: https://doi.org/10.36941/ajis-2020-0o88

\section{Abstract}

Small, Micro and Medium Entreprises (SMMEs) in South African townships, as in many countries worldwide, has a high failure rate. Effective use of marketing and other initiatives made available by the South African government, can help to decrease the number of failures. In order to assist SMMEs effectively, it is necessary to know how they approach marketing, what their training needs are and if they are aware of the initiatives available to assist them with various business functions. A survey was conducted in this regard with small business owners across South African townships. It can be concluded from the research that marketing plays a vital role in the growth and sustainability of a SMME. SMMEs that experienced a decline in growth in the previous year required more marketing training. The growth decline ratio is 1:1.08. It is furthermore clear from the marketing approach in relation to turnover ratios, that SMMEs that grew in turnover over the past three years are almost twice as active in performing marketing functions as the SMMEs that experienced a decline in turnover in the past three years. The need for marketing training was also pointed out as the most poignant training required by SMMEs. It can thus be deduced that the role and importance thereof cannot be overstated since the need expressed warrants the importance. The majority of respondents also indicated that they are not aware of any governmental programmes to assist SMMEs with their marketing..

Keywords: marketing communication, marketing training, township, government initiatives, SMMEs

\section{Introduction}

According to Statistics South Africa (2017), South Africa's national unemployment rate is one of the highest in the world at $\mathbf{2 7 . 7 \%}$ in the last quarter of 2017 . Government has made SMMEs a priority growth sector in South Africa in order to create employment opportunities and to grow the economy (OECD 2017). With five out of seven SMMEs failing within the first year, more support needs to be provided to current as well as new SMMEs (Entrepreneur 2015).

In a previous study by Abor and Qaurtey (2010:218) it was noted that in South Africa SMMEs account for $91 \%$ of formal businesses and that these SMMEs contribute up to $57 \%$ to the South African GDP. With the current economic conditions in the world as well as the increasing rate of unemployment, specifically in South Africa, SMMEs are becoming even more important. Unemployment is however a world-wide problem and similar problems are experienced by countries 
such as Ghana, Brazil, Asia and European union countries (European Commission 2013:9, Abor \& Quartey 2010:218).

Usually, countries comprise of two separate geographic areas namely rural and urban, but in South Africa it also includes townships and informal settlements that house close to half of South Africa's urban population (The World Bank 2014). Further, according to The World Bank (2014), South African townships and informal settlements house approximately $38 \%$ of working age citizens in South Africa but nearly $60 \%$ of township residents are unemployed.

The National Development Plan (NDP) of the South African government set a goal to triple the size of South Africa's economy by 2030 (National Planning Commission, 2015) which is largely centred on the development of the SMME sector. In order to achieve this objective it is imperative that SMMEs are assisted in any way possible to survive and to make a contribution to the economy of the country. However, many SMMEs are closing their doors for business every year and this is not solely due to unpredictable or unstable external conditions. Many of these closures can be attributed to management not being able to react and make correct decisions with regard to the changes in the business environment (Williams 2014:91). This problem of not reacting to changes correctly needs to be addressed in order for SMME's to be able to function better and to contribute to economic growth and development. A strategic business plan, which includes marketing, may assist in reducing this problem by providing a clear roadmap that guides SMMEs towards the successful running of their businesses. The question can thus be asked: do SMMEs operating in South African townships see marketing as a contributor to business sustainability and success? Given the goal to triple the size of the economy, which is mainly centred on the development of the SMME sector, another question can be asked: are SMME's aware of the initiatives from government to support and promote the sector?

This study makes several key contributions at contextual and managerial levels. At a contextual level, the study contributes knowledge with regards to the marketing practices of SMMEs in townships in South Africa. On a managerial level, the study contributes to managerial practices by underscoring the importance of marketing in SMMEs.

\section{Literature Review}

\subsection{The importance of marketing in business development}

Marketing is defined by Kotler and Keller (2012:28) as “...meeting needs profitably". It is about knowing and understanding the consumer in such a way that you can tailor a product or service that meets the customers' needs. Customers will be happier and thereby the company will be more profitable (Iacobucci 2018).

In order for a business to be profitable, it is imperative for companies to plan their marketing strategy carefully. When a clear marketing strategy is developed the company will know exactly who their market is, why they buy from them and what type of marketing they should use to reach a specific audience, which in turn can result in a higher return on investment (Dryburgh, 2009:14). Resnick, Cheng, Simpson and Lourenço (2016) however argue that in small businesses, marketing is not formally planned, but seen as opportunistic and intuition is often used to describe why certain activities occur. Hulbert et al (2013) agrees and indicates that conventional marketing theories that emphasises planning, marketing research, advertising and the marketing mix are more typically intended for large organisations where financial resources and marketing expertise are readily available. Marketing is an integral part of business operations and is usually instigated and undertaken by the owner and every other employee with no separate department that is responsible for marketing in the business (Reijonen 2010; Resnick, Cheng, Simpson \& Lourenço 2016). Obstacles to marketing by SMMEs include financial restrictions, time and expertise (Reijonen 2010; CroninGilmore 2012; Resnick et al. 2013).

A marketing strategy and objectives provide the organisation with detailed and measurable targets that can drive an organisation towards achieving the goals that they set (Ferrell \& Hartline, 
2011:144). With the limited resources that small businesses have, they cannot afford to not reach their intended target market and money spent should result in sales and profit. Thus, planning of a marketing strategy is not only important for big corporations with generous marketing budgets but even more so for SMMEs with limited marketing budgets since marketing is a form of communication. Marketing on a continuous basis will increase profitability and growth of the business and should be seen as an investment rather than an expense (Groenewald, Prinsloo \& Pelser, 2014).

\subsection{Global integrated marketing communication usage by SMMEs}

Organisations make use of marketing communication to inform, persuade, remind or connect with existing and potential customers. The marketing communication mix consists of advertising, public relations, sales promotion, personal selling, content marketing and social media (Lamb, Hair \& McDaniel 2018). All of these marketing communication elements can be used successfully by SMMEs depending on certain factors. These factors include the nature of the product, the stage in the product life cycle, the target market characteristics, the available funds and the push and pull strategies (Lamb, Hair \& McDaniel 2018). Advertising, public relations, sales promotion and personal selling are considered as traditional marketing communication. This can be either offline or online or both. Whereas, content marketing and social media are known as e-marketing communication and is fully online. The types of traditional marketing communication tools to SMMEs disposal include word-of-mouth, pamphlets, printed banners, hosting events and advertising on radio or in newspapers. E-marketing communication tools that SMMEs have to their disposal include social media platforms like Facebook, Twitter, Instagram and LinkedIn.

\subsubsection{Traditional and e-marketing communication}

Several studies have been conducted on the use of traditional marketing communication used by SMMEs globally. In the UK, word-of-mouth referrals emerged as the most important marketing activity followed by building long-term relationships (Resnick et al. 2013). SMMEs did not make use of press, television advertising and public relations as it is perceived as being expensive, aggressive, insincere and not value for money (Resnick et al. 2013). South African SMMEs reported using advertising (including brochures/pamphlets), sales promotions in the form of special offers, and personal selling (Lekhanya 2015).

In first world countries, the most used online marketing communication elements by SMMEs include websites and social media. In a study conducted in Finland, online visibility was considered the most important element of the digital marketing mix as websites and SEO were most used (Taiminen \& Karjaluoto 2015). In the UK, websites were also deemed an important communication element but was not monitored by owners (Resnick et al. 2013). Social media enables companies to build relationships with customers anywhere in the world (Bolotaeva \& Cata 2011). Social media can hold opportunities for SMMEs with limited budgets. SMMEs make use of social media marketing to promote their companies, to gain visibility and to sustainably survive in the competitive environment (Tanjela \& Toombs 2014). Taiminen and Karjaluoto (2015) however argued that SMMEs lack knowledge of online marketing, which results in SMMEs not using these tools to their full potential and thus not benefitting fully from it. In developing countries, like South Africa, online marketing is not the most used marketing communication element, especially in townships. Government plays a vital role in teaching SMMEs in learning how to use these different types of e-marketing tools.

\subsection{Government assistance for SMMEs}

With government's vested interest in the success of the SMME sector, the support of government in the development of the SMME sector is of great importance. Factors which influence viability of 
SMMEs in the Vaal Triangle in South Africa for example, were identified by Worku (2016) as difficulty in securing loans, lack of training opportunities, and shortage of entrepreneurial skills. The South African government recognised the importance of the sector and established a Ministry of Small Business Development to facilitate the promotion and development of small businesses in South Africa (The Small Enterprise Development Agency 2016). Over and above funding initiatives, the South African government has partnerships in place to provide SMMEs with further support in developing business plans, conducting market research, managing a small business, legal requirements, marketing, business development and advice on tender processes (The Small Enterprise Development Agency 2016).

With all the support available to SMME's by the government, it is alarming that the majority of SMMEs still fail in the first three years (Worku 2016). In a previously conducted study, the lack of marketing skills and financial problems experienced by business were two of the reasons identified for business failure (Cant, 2012).

\section{Aim and Objectives of the Study}

The above discussion highlights the role and importance of marketing for SMMEs as well as the importance of government assistance to SMMEs to reach their overall target of job creation and growth in the economy. The correct application of marketing strategies can “...benefit SMMEs by securing transactions, while producing a range of relational benefits, acquiring and retaining customers, generating positive word of mouth and increasing the client base" (Ahmad \& Saber 2015). With this in mind, the primary aim of this study is to investigate the role and importance of marketing in township SMMEs. This primary aim is supported by the following research objectives:

- To determine which marketing communication elements SMMEs are using in South African townships.

- To explore what the training need of SMMEs in South African townships are.

- To determine if SMMEs in South African townships are aware of the available government assistance programmes.

\section{Methodology}

\subsection{Procedure and design}

The study adopted an explorative approach utilizing a survey questionnaire to collect data from various SMMEs across townships in South Africa. The townships selected covered all the major provinces including the Western Cape, KwZulu-Natal, Gauteng, Limpopo, Mpumalanga, and Free State. For the purpose of this study, several questions pertaining to businesses in Townships, as well as the role and importance of marketing in township SMMEs, were included.

\subsection{Sample}

The total sample for the study consisted of 498 respondents $(\mathrm{N}=498)$ with the majority being African $(\mathrm{n}=377,75.7 \%)$. In terms of gender, 299 respondents were male $(60 \%)$ with 185 females (37.1\%). Table 1 below provides a detailed demographic breakdown of the sample: 
Table 1: Demographic breakdown of sample

\begin{tabular}{lcc}
\hline & n & Percentage \\
\hline Race & 377 & $75 \cdot 7$ \\
African & 15 & 3.0 \\
White & 39 & 7.8 \\
Coloured & 30 & 6.0 \\
Indian & 21 & 4.2 \\
Other & 16 & 3.2 \\
Missing & & \\
\hline Gender & 299 & 60.0 \\
\hline Male & 185 & 37.1 \\
Female & 14 & 2.9 \\
Missing & & \\
\hline Age & 45 & 9.0 \\
\hline $18-25$ & 93 & 18.7 \\
$26-30$ & 116 & $23 \cdot 3$ \\
$31-35$ & 94 & 18.9 \\
$36-40$ & 91 & 18.3 \\
$41-50$ & 40 & 8.0 \\
$51-60$ & 6 & 1.2 \\
Older than 6o & 13 & 2.6 \\
Missing & &
\end{tabular}

Table 2 below provides a breakdown of the type of SMMEs respondents are involved in., This table serves as an indicator of the sector in which the SMMEs operate which can have an impact on the ultimate strategy that can be followed.

Table 2: Type of business

\begin{tabular}{lcc}
\hline & n & Percentage \\
\hline Type of Business & & \\
\hline Service Providers/Stores & 113 & 22.7 \\
Food & 78 & $15 \cdot 7$ \\
Retail/Goods Stores & 42 & 8.4 \\
Salon/Beauty & 41 & 8.2 \\
Tuckshop/Spaza Shops & 39 & 7.8 \\
Internet/Electronic Stores & 20 & 4.0 \\
Day Care & 16 & 3.2 \\
Funeral Parlour/Services & 16 & 3.2 \\
Construction & 14 & 2.8 \\
Manufacturing & 13 & 2.6 \\
Clothing & 13 & 2.6 \\
Medical & 9 & 1.8 \\
Entertainment & 8 & 1.6 \\
Accommodation & 8 & 1.6 \\
Security & 3 & 0.6 \\
Other & 22 & 4.4 \\
Missing & 43 & 8.6 \\
\hline
\end{tabular}

The majority of respondents $(\mathrm{n}=113,22.7 \%)$ indicated that they are involved in businesses which provide services- which is not surprising as manufacturing for example normally requires more and better infrastructure. These services include mechanical services, garden services, carwash services, repair services, welding services, upholstery services, transport services, dry cleaning services as well 
as various business services, such as bookkeeping, printing and communications. The other major types of businesses respondents highlighted, included the food industry $(n=78,15.7 \%)$ which include restaurants, catering, taverns and liquor stores. Various retail stores $(\mathrm{n}=42,8.4 \%)$, hair and beauty salons $(n=41,8.2 \%)$ and tuckshops or spaza shops $(n=39,7.8 \%)$, were also among the types of businesses predominantly identified by the respondents.

\subsection{Data analysis}

Thematic analyses and basic descriptive statistics were utilised to identify the main themes which stemmed from the data with frequencies and percentages serving as a robust indication as to the relevance or importance of the extracted themes.

\section{5. $\quad$ Findings and Results}

In order to explore the role and importance of marketing in township SMMEs, the results will be presented, firstly by discussing the dominant reasons behind an increase of turnover, for the past 3 years, for some SMME owners. Furthermore, the perception regarding which training is deemed as most required by SMME owners will be examined. Following this, the current marketing approaches as well as the social media platforms utilised by SMMEs will be discussed. Finally, the awareness of governmental marketing assistance programmes by SMMEs will be examined.

\section{1 $\quad$ Marketing implications on turnover and training required}

In order to investigate the role and importance of marketing in township SMMEs, respondents were required to indicate whether their turnover grew, declined or stayed the same over the preceding three years.

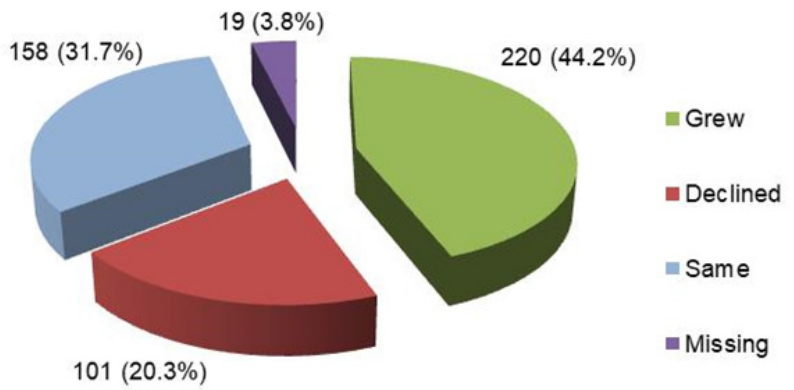

Figure 1: Turnover in last 3 years

As depicted in Figure 1, the majority $(75,9 \%)$ of SMMEs' turnover remained the same $(31,7 \%)$ or grew $(44,2 \%)$ in the last three years. A minority $(20,3 \%)$ experienced a decline in turnover. With $52 \%$ of SMMEs' turnover declining or staying the same, it may indicate that a contributing factor can be a lack of marketing by SMMEs although other contributing factors cannot be excluded. This lack of growth however further highlights the importance and need of marketing for SMMEs. Table 3 below provides a breakdown of the main reasons identified by respondents that indicated a growth in their turnover: 
Table 3: Reasons for growth in turnover

\begin{tabular}{lcc}
\hline Turnover Grew $(\mathbf{n}=\mathbf{2 2 0})$ & $\mathbf{n}$ & Percentage \\
\hline Improved my marketing & 161 & 73.2 \\
Cost-saving measures & 106 & 48.2 \\
More people unemployed & 55 & $\mathbf{2 5 . 0}$ \\
Too much competition & 47 & 21.4 \\
Economy is bad & 39 & 17.7 \\
Reputation/Word of Mouth & 2 & 10.0 \\
Other & 20 & 9.1 \\
\hline Other* Themes (n= 2o) & & \\
\hline Expanding business & 7 & 35.0 \\
Lack of competition & 3 & 15.0 \\
Government support/tenders & 3 & 15.0 \\
Growing market & $\mathbf{2}$ & 10.0 \\
Loyalty from customers & 2 & 10.0 \\
Hard work/effort & 1 & 5.0 \\
Quality service/products & 1 & 5.0 \\
\hline
\end{tabular}

${ }^{*}$ Respondents indicated more than one element thus total $\mathrm{n} \&$ total percentage $>100 \%$

The majority of respondents $(\mathrm{n}=161,73.2 \%$ ) indicated 'improved my marketing' as the main reason for a growth in turnover which seems to indicate that marketing made an important contribution to increased sales - something the other respondents should maybe have focussed on more. Furthermore, $48.2 \%(n=106)$ of respondents indicated they implemented 'cost-saving measures' which improved profits.

In addition to the above, respondents were asked to indicate the specific training they think is required in order to improve their businesses. Table 4 below provides a breakdown of the most important training required:

Table 4: Training required based on turnover

\begin{tabular}{|l|c|c|c|c|c|c|}
\hline \multirow{2}{*}{ Training Needs } & \multicolumn{2}{|c|}{ Grew $(\mathbf{n}=\mathbf{2 2 0})$} & \multicolumn{2}{c|}{ Declined $(\mathbf{n = 1 0 1})$} & \multicolumn{2}{c|}{ Stayed the same (n= 158) } \\
\cline { 2 - 7 } & $\mathrm{n}$ & $\%$ & $\mathrm{n}$ & $\%$ & $\mathrm{n}$ & $\%$ \\
\hline Marketing & 139 & 63.2 & 69 & 68.3 & 99 & 62.7 \\
\hline Financial Training & $\mathbf{1 2 4}$ & 56.4 & 57 & 56.4 & 103 & 65.2 \\
\hline Management & 115 & 52.3 & 56 & 55.4 & 86 & 54.4 \\
\hline Admin & 83 & 37.7 & 29 & 28.7 & 59 & 37.3 \\
\hline Purchasing & 75 & 34.1 & $\mathbf{2 2}$ & $\mathbf{2 1 . 8}$ & 45 & $\mathbf{2 8 . 5}$ \\
\hline Other & $\mathbf{2 4}$ & $\mathbf{1 0 . 9}$ & 8 & 7.9 & $\mathbf{1 1}$ & 7 \\
\hline
\end{tabular}

The main area where respondents felt a need for training was in marketing $(\mathrm{n}=307,61.64 \%)$, while $57.03 \%(n=284)$ of respondents indicated that they had a need for financial training. Based on percentages, a comparison was drawn between the training required and turnover. The ratios were calculated with a growth in turnover as baseline, (see Table 5).

Table 5: Training required based on turnover ratio

\begin{tabular}{|l|c|c|c|}
\hline Training Required & Grew & Declined & Stayed the same \\
\hline Marketing & $\mathbf{1}$ & $\mathbf{1 . 0 8}$ & $\mathbf{0 . 9 9}$ \\
\hline Financial Training & 1 & $\mathbf{1 . 0 0}$ & $\mathbf{1 . 1 6}$ \\
\hline Management & 1 & 1.06 & $\mathbf{1 . 0 4}$ \\
\hline Admin & 1 & 0.76 & 0.99 \\
\hline Purchasing & 1 & 0.64 & 0.84 \\
\hline Other & 1 & 0.72 & 0.64 \\
\hline
\end{tabular}


It is evident from Table 5 that respondents of SMMEs that experienced a decline in turnover during the past three years, might benefit from more marketing training. The ratio is $1: 1.08: 0.99$. This means that for every 1 (one) SMME that experienced growth, there is 1,08 (one comma zero eight) SMMEs that experienced a decline and 0.99 (zero comma nine nine) SMMEs that experienced a stay in turnover, which is an indication that marketing training is required.

\subsection{Current marketing communication in relation to turnover}

In order to further explore the role and importance of marketing in township SMMEs, respondents were required to indicate what form of marketing they are currently applying in the business. Respondents were not limited in the amount of options they could select. Table 6 below provides a breakdown of the current forms of marketing which business owners engage in:

Table 6: Current marketing in relation to turnover

\begin{tabular}{|c|c|c|c|c|c|c|c|c|}
\hline \multirow[b]{2}{*}{ Type of marketing } & \multicolumn{2}{|c|}{ Grew } & \multicolumn{2}{|c|}{ Declined } & \multicolumn{2}{|c|}{ Stayed same } & \multicolumn{2}{|c|}{ Total } \\
\hline & $\mathbf{n}$ & $\%$ & $\mathbf{n}$ & $\%$ & $\mathbf{n}$ & $\%$ & $\mathbf{n}$ & $\%$ \\
\hline Word of mouth & 159 & 72.3 & 61 & 60.4 & 98 & 62.0 & 318 & 63.86 \\
\hline Personal selling & 103 & 46.8 & 39 & 38.6 & 79 & 50.0 & 221 & $44 \cdot 38$ \\
\hline Social media & 103 & 46.8 & 26 & 25.7 & 63 & 39.9 & 192 & 38.55 \\
\hline Pamphlets & 78 & $35 \cdot 5$ & 29 & 28.7 & 47 & 29.7 & 154 & 30.92 \\
\hline Banners & 42 & 19.1 & 17 & 16.8 & 24 & 15.2 & 83 & 16.67 \\
\hline Events & 52 & 23.6 & 12 & 11.9 & 14 & 8.9 & 78 & 15.66 \\
\hline Radio & 44 & 20.0 & 8 & 7.9 & 6 & 3.8 & 58 & 11.65 \\
\hline Newspaper & 33 & 15.0 & 7 & 6.9 & 9 & $5 \cdot 7$ & 49 & 9.84 \\
\hline Nothing & 4 & 1.8 & 18 & 17.8 & 12 & 7.6 & 34 & 6.83 \\
\hline Other & 11 & 5.0 & 10 & 9.9 & 6 & 3.8 & 27 & 5.42 \\
\hline
\end{tabular}

The main types of marketing identified by respondents regarding whether there was a growth, decline or stay in the turnover, included Word of Mouth $(63,86 \% ; n=318)$, Personal Selling $(44.38 \%$; $\mathrm{n}=221$ ), Social Media $(38.55 \% ; n=192)$ and Pamphlets $(30.92 \% ; n=154)$. 'Other' $(\mathrm{n}=27,5.42 \%)$ responses ranged from door-to-door selling/surveys, car branding and providing of discounts. No dominant theme emerged from the other responses (see Table 9). Based on percentages, a comparison was drawn between the marketing approach and turnover. The ratio was calculated with a growth in turnover as baseline (see Table 7 ).

Table 7: Current marketing in relation to turnover ratio

\begin{tabular}{|l|c|c|c|}
\hline Type of marketing & Grew & Declined & Stayed the same \\
\hline Word of mouth & 1.00 & 0.84 & 0.86 \\
\hline Personal selling & 1.00 & 0.82 & 1.07 \\
\hline Social media & $\mathbf{1 . 0 0}$ & $\mathbf{0 . 5 5}$ & $\mathbf{0 . 8 5}$ \\
\hline Pamphlets & 1.00 & 0.81 & 0.84 \\
\hline Banners & 1.00 & 0.88 & 0.80 \\
\hline Events & $\mathbf{1 . 0 0}$ & $\mathbf{0 . 5 0}$ & $\mathbf{0 . 3 8}$ \\
\hline Radio & $\mathbf{1 . 0 0}$ & $\mathbf{0 . 4 0}$ & $\mathbf{0 . 1 9}$ \\
\hline Newspaper & $\mathbf{1 . 0 0}$ & $\mathbf{0 . 4 6}$ & $\mathbf{0 . 3 8}$ \\
\hline Nothing & 1.00 & 9.89 & 4.22 \\
\hline Other & 1.00 & 1.98 & 0.76 \\
\hline
\end{tabular}

As depicted in Table 7, the main difference in marketing approaches applied between those that 
experienced a growth in turnover, and those that experienced a decline or stay in turnover, are radio. SMMEs that experienced growth, was almost twice as active when it comes to the use of the radio (with a ratio $1: 0.40: 0.19$ ) in comparison with the SMMEs that experienced a decline and almost five times more active than the SMMEs that experienced a stay in turnover. Newspapers with a ratio of 1 : $0.46: 0.38$, Events with a ratio of $1: 0.5: 0.38$ and Social media with a ratio of $1: 0.55: 0.85$.

Respondents that indicated the utilisation of social media, were asked to further indicate which platforms they utilise. No limit was placed on the number of options that could be selected. Table 8 below provides a breakdown of the different platforms employed by the owners utilising social media:

Table 8: Social media marketing in relation to turnover

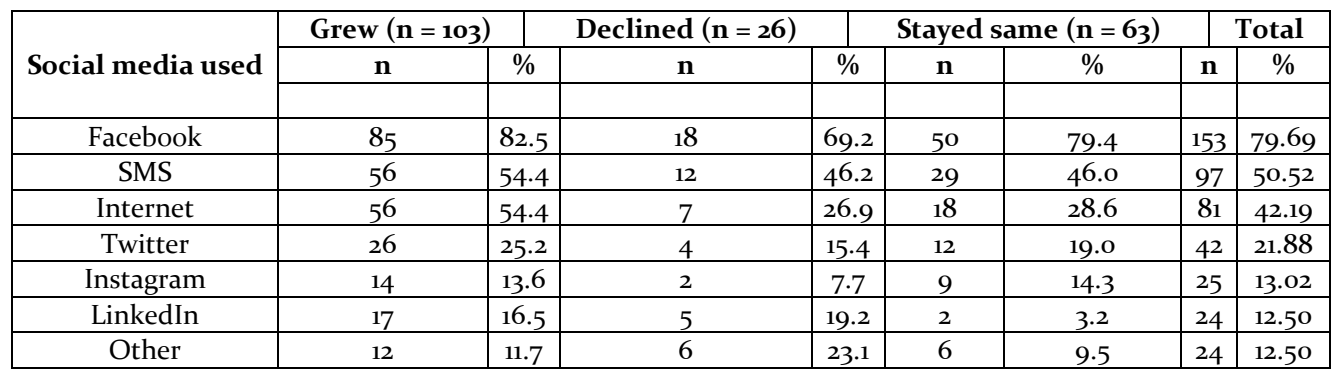

${ }^{*}$ Respondents indicated more than one element thus total $\mathrm{n} \&$ total percentage $>100 \%$

The majority of respondents $(\mathrm{n}=153,79.69 \%)$ indicated that they use Facebook as the main platform for social media marketing, while respondents who utilized SMS $(\mathrm{n}=97,50.52 \%)$ and the Internet $(\mathrm{n}$ $=81,42.19 \%)$ emerged as also important social media platforms utilized. Respondents who selected the 'other' option $(n=24,12.5 \%)$ mainly noted the use of WhatsApp as the social media platform that they use.

Based on percentages, a comparison was drawn between the social media marketing platform used and turnover. The ratio was calculated with a growth in turnover as baseline, (see Table 9).

Table 9: Social Media marketing in relation to turnover ratio

\begin{tabular}{|l|c|c|c|}
\hline Social Media Platform & Grew & Declined & Stayed the same \\
\hline Facebook & 1.00 & 0.84 & 0.96 \\
\hline SMS & 1.00 & 0.85 & 0.85 \\
\hline Internet & 1.00 & 0.49 & 0.53 \\
\hline Twitter & 1.00 & 0.61 & 0.75 \\
\hline Instagram & 1.00 & 0.57 & 1.05 \\
\hline LinkedIn & 1.00 & 1.16 & 0.19 \\
\hline Other & 1.00 & 1.97 & 0.81 \\
\hline
\end{tabular}

As depicted in Table 9, the main difference in the social media marketing platform used between the SMMEs that experienced a growth in turnover and the SMMEs that experienced a decline, or stay in turnover, is the Internet with a ratio of $1: 0.49: 0.53$. This means that the SMMEs that experienced a growth was almost twice as active when it comes to the use of the Internet in comparison to the SMMEs that experienced a decline and stay in turnover. Instagram with a ratio of $1: 0.57: 1.05$ and Twitter with a ratio of $1: 0.61: 0.75$.

\subsection{Governmental marketing assistance programmes}

Respondents were asked if they are aware of any government programmes that can help and assist 
SMMEs with their marketing. Figure 2 below provides a breakdown of the responses pertaining to awareness of any government programmes that can help and assist SMMEs with their marketing by means of social media:

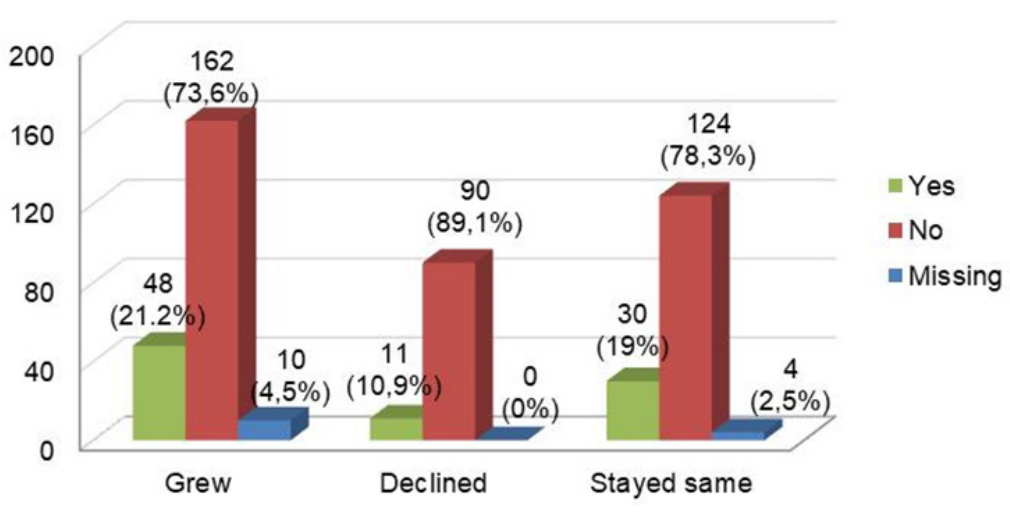

Figure 2: Awareness of government programmes

The majority of respondents, regardless whether the turnover of the SMME had grew $(73.6 \% ; n=162)$, declined $(89.1 \% ; n=90)$ or stayed the same $(78.3 \% ; n=124)$ over the past three years, indicated that they are not aware of any such programmes to assist SMMEs with their marketing by means of social media. In contrast, $21.2 \%(n=48)$ of SMMEs that experienced growth, $10.9 \%(n=11)$ that experienced a decline in turnover and $19 \%(\mathrm{n}=124)$ that experienced a stay in turnover indicated awareness of such programmes.

Table 1o below provides a breakdown pertaining to specified programmes that respondents are aware of.

Table 10: Awareness of offered programmes

\begin{tabular}{|l|c|c|}
\hline Programmes to assist with marketing $(\mathbf{n}=\mathbf{8 9})$ & $\mathbf{n}$ & Percentage \\
\hline SEDA/NYDA & 23 & 25.8 \\
\hline Municipal/Government & 8 & 9.0 \\
\hline SASETA & 3 & 3.4 \\
\hline Other & 9 & 10.1 \\
\hline Missing & 46 & 51.7 \\
\hline
\end{tabular}

The Small Enterprise Developmental Agency (SEDA) along with the National Youth Development Agency (NYDA) were identified by $25.8 \%(n=23)$ of the respondents as the primary providers of programmes to assist with social media marketing, while $9 \%(n=23)$ of respondents also highlighted Municipal/Governmental programmes. The specific programmes provided by these providers were however not elicited from the responses in the questionnaire. These responses is a clear indication that there is not a high level of awareness of these programmes amongst SMMEs

\section{Discussion}

It can be deduced from the above, that marketing plays a vital role in the growth and sustainability of 
a SMME. SMMEs that experienced a decline in growth would seem to be in need of some marketing training. It is furthermore clear from the marketing approach in relation to turnover ratios, that SMMEs that grew in turnover over the past three years are almost twice as active in performing marketing functions as the SMMEs that experienced a decline in turnover in the past three years.

The data attributes an improvement in marketing as the main reason for a growth in turnover over the past three years by those SMMEs who reported a growth, thus, clearly indicating the importance of marketing with regards to business growth and sustainment.

The need for marketing training was also been pointed out as the most poignant training required by SMMEs. It can thus be deduced that the role and importance thereof cannot be overstated since the need expressed warrants the importance.

Word of mouth, followed by personal selling, emerged as the most dominant approaches followed by current owners in terms of marketing. These can however be viewed as more traditional ways of marketing being employed. Social media was also highlighted as a primary approach in order to conduct marketing with Facebook, being the most utilised platform in order to do so. In the current day and age, where most individuals have access to social media via a phone or computer, the need to utilise social media for marketing may be key and may potentially arise as the preferred way of conducting marketing in the future.

The majority of respondents however indicated that they are not aware of any governmental programmes to assist SMMEs with their marketing by means of social media. As highlighted above, the need for marketing training coupled with the importance of social media in marketing and the current void of such programmes, creates an avenue where the government and other organisations can get involved and assist the SMME owner in potentially growing his/her business through the implementation of social media marketing.

\section{Conclusion}

The importance and role of marketing in the success of the SMMEs cannot be underestimated. In light of the current economic environment, business owners will have to pursue innovative and traditional ways of marketing in order to ensure the long-term growth and success of their businesses. Social media may be one of those avenues, and training in the utilisation thereof could potentially be beneficial to the SMME owner in order to ensure the growth and sustainment of the business.

\section{References}

Anon. 2015. Top 5 things SMMEs want from government. Fin24. [Available online: www.fin24.com/Entrepreneurs/News/Top-5-things-SMMEs-want-from-government-20151007 Accessed: 2609-2017.

Ahmad, S.Z. \& Saber, H. 2015. Understanding marketing strategies with particular reference to small-andmedium-sized hotel businesses in the United Arab Emirates. Tourism and Hospitality Research, 15(2): 115 129.

Bolotaeva, V. \& Cata, T. 2011. Marketing opportunities with social networks. Journal of Internet Social Networking and Virtual Communities, 10.

Cant, M.C. 2012. Challenges faced by SMMEs in South Africa: Are marketing skills needed? International Business $\mathcal{E}$ Economics Research Journal, 11(10): 1107 - 1116.

Cant, M.C. \& van Heerden, C.H. 2010. Marketing management: A South African perspective. Cape Town: Juta.

Cronin-Gilmore, J. 2012. Exploring marketing strategies in small businesses. Journal of Marketing Development and Competitiveness, 6(1): $96-107$.

Entrepreneur, (2015), "Small business", [Online] Available at: http://www.entrepreneurmag .co.za/advice/startinga-business/small-business-advice/small-business/ [Accessed: 2017-09-17].

Groenewald, A.C., Prinsloo, J.J. \& Pelser, T.G. 2014. Strategic marketing insights for small business meat retailers. International Business E Economics Research Journal, 13(3): 525 - 538. 
Hulbert, B., Gilmore, A. \& Carson, D. 2013. Sources of opportunities used by growth minded owner managers of small and medium sized enterprises. International Business Review, 22(1): 293 - 303.

Iacobucci, D. 2018.Marketing Management. $5^{\text {th }}$ Edition. Cengage Learning: Boston.

Kotler, P. \& Keller, K.L. 2012. A framework for marketing management. 5 th edition, Pearson: Essex.

Lamb, C.W., Hair, J.F. \& McDaniel, C. 2018.MKTG ${ }^{\text {11 }}$ Principles of Marketing. $\mathbf{1 1}^{\text {th }}$ edition, Cengage Learning: Boston.

National Planning Commission, 2015. National Development Plan - 2030. [Online] Downloaded from: https://www.brandsouthafrica.com/wp_download_viewer.php?file=wp-content/uploads/brandsa/2015/o5/ 02_NDP_in_full.pdf [Download" 2018-04-30].

OECD. 2017. South Africa: Find new ways to boost growth and job creation [Online] Available from: http://www.oecd.org/southafrica/south-africa-find-new-ways-to-boost-growth-and-job-creation.html [Downloaded: 2018-04-30].

Patricios, O. 2009. Social media will reinvent brands. [Online] Available from: http://reference.sabinet.co.za/webx/access/electronic_journals/mfsa1/mfsa1_apr_2009_a16.pdf [Downloaded: 2015-04-15].

Reijonen, H. 2010. Do all SMMEs practise same kind of marketing? Journal of Small Business and Enterprise Development, 17(2): 279 - 293.

Resnick, S.M., Cheng, R., Simpson, M. \& Lourenço, F. 2016. Marketing in SMMEs: A “4Ps” self-branding model. International Journal of Entrepreneurial Behaviour and Research, 22(1): 155 - 174 .

Safko, L. 2010. The social media bible: Tactics, tools and strategies for business success. Hoboken, Hoboken: John Wiley \& Sons.

Safko, L. \& Brake, D.K. 2009. The social media bible: Tactics, tools and strategies for business success. Hoboken, N.J.: John Wiley \& Sons.

Statistics South Africa. 2017 Quarterly Labour Force Survey - QLFS Q1:2017. Available online: http://www.statssa.gov.za/?p=996o Accessed: 2017-09-28.

Tanjeal, S. \& Toombs, L. 2014. Putting a face on small businesses: Visibility, viability, and sustainability the impact of social media on small business marketing. Academy of Marketing Studies, 18(1): 249 - 260.

The Small Enterprise Development Agency. 2016. The small, medium and micro enterprise sector of South Africa. Research Note 2016 No 1. Bureau of Economic Research Available online: http://www.seda.org.za/Publications/Publications/The Small, Medium and Micro Enterprise Sector of South Africa Commissioned by Seda.pdf

The World Bank. 2014. The Economics of South African Townships http://www.worldbank.org/en/country/southafrica/publication/the-economics-of-south-african-townshipsspecial-focus-on-diepsloot

Visser, T., Chodokufa, K., Amadi-Echendu, A \& Phillips, M. 2016. An analysis of small business skills in the City of Tswane, Gauteng Province. African Journal of Business and Economic Research, 11(1): 93 - 115.

Worku, Z. 2016. Barriers to the growth of small, micro and medium-sized business enterprises in the Vaal Triangle region of South Africa. African Journal of Science, Technology, Innovation and Development, 8(2): 134 - 141.

Xiang, Z. \& Gretzel, U. 2010. Role of social media in online travel information search. Tourism Management, 31 : 179 -188 . 